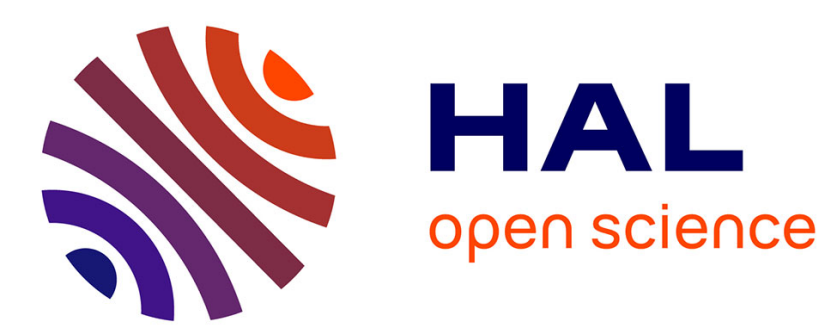

\title{
Flow control of two-level assembly lines
}

Ahmedou Haouba, Xiaolan Xie

\section{To cite this version:}

Ahmedou Haouba, Xiaolan Xie. Flow control of two-level assembly lines. [Research Report] RR-1866, INRIA. 1993, pp.14. inria-00074807

\section{HAL Id: inria-00074807 https://hal.inria.fr/inria-00074807}

Submitted on 24 May 2006

HAL is a multi-disciplinary open access archive for the deposit and dissemination of scientific research documents, whether they are published or not. The documents may come from teaching and research institutions in France or abroad, or from public or private research centers.
L'archive ouverte pluridisciplinaire HAL, est destinée au dépôt et à la diffusion de documents scientifiques de niveau recherche, publiés ou non, émanant des établissements d'enseignement et de recherche français ou étrangers, des laboratoires publics ou privés. 


\section{Flow control of two-level assembly lines}

Ahmedou HAOUBA

Xiaolan XIE

No 1866

Mars 1993

PROGRAMME 5

Traitement du Signal,

Automatique et

Productique

\section{apport}

derecherche 


\title{
Contrôle de Flux dans les systèmes d'assemblage à deux niveaux
}

\author{
Ahmedou HAOUBA \\ Institut Supérieur Scientifique, Nouakchott, Mauritanie \\ Xiaolan XIE \\ INRIA, Technopôle Metz 2000, 4 Rue Marconi, 57070 Metz, France
}

\section{RESUME}

Dans ce papier, nous nous intéressons au contrôle de flux dans les systèmes d'assemblage à deux niveaux. Un tel système est composé d'une machine d'assemblage alimentée par plusieurs machines du niveau supérieur qui fabriquent des composants. La capacité de chaque machine est constante et la demande est connue sur l'horizon complet. Les ruptures de stocks interdites. Le problème du contrôle de flux consiste à ajuster la production de chaque machine de manière à minimiser la somme des coûts engendrés par les stocks intermédiaires et le stock du produit fini. Nous établissons des propriétés de solutions optimales et proposons une solution analytique. 


\title{
Flow Control of Two-Level Assembly Lines *
}

\author{
Ahmedou HAOUBA + \\ Institut Supérieur Scientifique, Nouakchott, Mauritanie
}

Xiaolan XIE

INRIA, Technopôle Metz 2000, 4 Rue Marconi, 57070 Metz, France

\begin{abstract}
The paper addresses the flow control problem in two-level assembly production lines composed of a unique assembly machines and multiple upper level machines. In order to obtain a finished product, the assembly machine needs components produced by different upper level machines. We assume that the production capacity of each machine is constant and the the demand is known over the whole problem horizon. Backlogging is not allowed. The flow control problem consists of adjusting the production of the machines in order to minimize the total cost incurred by holding components and finished products. Properties of the optimal solutions are given. Based on these properties, we propose a simple analytical solution.
\end{abstract}

\footnotetext{
"Mailing address : Dr XIE Xiaolan, SAGEP Project/INRIA, Technopôle Metz 2000, 4 rue Marconi, 57070 Metz, France. E-Mail : xie@ilm.loria.fr. Fax : (33) 87763977

+ This work was done while the first author was visiting INRIA
} 


\section{INTRODUCTION}

A two level assembly line is composed of a unique assembly machine and several upper level machines (see Figure 1). First, components are produced by the upper level machines and stocked in the buffers associated with the machines. In order to obtain a finished product, the assembly machine needs a given number of components from each of the upper level buffers. The rate at which a machine produces is called production rate. We assume that the maximal production rate (or capacity) of each machine is constant and that the demand is known over the whole problem horizon. Backlogging is not allowed. The flow control problem consists of adjusting the production of the machines in order to minimize the total cost incurred by holding components and finished products.

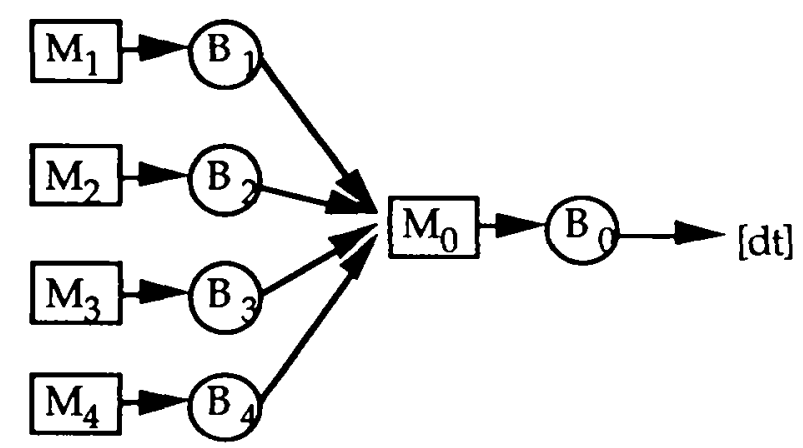

Figure 1: A two-level assembly line

Due to its importance in the control of manufacturing systems, flow control has been widely addressed for various types of production systems both in the deterministic case and the stochastic case (see [1-11]). In most of the existing work, mathematical programming models were proposed. Linear programming methods were used to find optimal flow control policies in deterministic case and dynamic programming approaches were used in the stochastic case.

This paper addresses the flow control in two-level assembly lines. Only the deterministic case is considered. The objective is to establish some important characteristics of the optimal control policies. In particular, we establish conditions under which the intermediate buffers are always empty, i.e. zero work-in-process. Conditions under which a particular buffer is always empty are also given. Finally, a simple algorithm is proposed for computing the optimal control policy.

To the best of our knowledge, the results presented in this paper are new. As a matter of fact, analytical solutions were proposed in [3,9] for the single machine case and in [6] for the transfer line case. However, no analytical solution has been proposed for the assembly line case. 
This paper is organized as follows. Section 2 describes the flow control model. Section 3 presents the results for the single machine case. These results are required for solving the general case. Section 4 first addresses the feasibility of the demand, and the characteristics of the optimal control policy. It then proposes optimal control policies. Section 5 presents a numerical example and Section 6 is a conclusion.

\section{PROBLEM SETTING}

Let us consider a two-level assembly line consisting of $n$ upper level machines $\left(M_{1}\right.$, $\left.M_{2}, \ldots, M_{n}\right)$ and a unique assembly machine $\left(M_{0}\right)$. There are $n$ component buffers $\left(B_{1}\right.$, $B_{2}, \ldots, B_{n}$ ) which separate the upper level machines from the assembly machine. There is a buffer $\left(B_{0}\right)$ of finished products.

A discrete time model is used in this paper. Let $\mathrm{H}$ be the number of elementary periods which is commonly called problem horizon.

The following notations will be used throughout the paper :

$W_{i}$ : the maximal production capacity of machine $M_{i}$ during each period

$u_{i, t}$ : the production of $M_{i}$ during period $t$

$d_{t}$ : the demand during period $t$

$s_{i, t}$ : the buffer level of $B_{i}$ at the end of period $t$

$c_{i}$ : the cost incurred by keeping one unit of product in $B_{i}$ at the end of a period

$\mathrm{q}_{\mathrm{i}}$ : number of components i needed to obtain a finished product

We assume that the demand $\left(d_{1}, \ldots, d_{H}\right)$ is known over the whole horizon. The control variables to be determined are $u_{i, t}$. The vector $\left[s_{0, t}, s_{1, t}, \ldots, s_{n, t}\right]$ describes the state of the system at the end of period $t$.

We further assume that the buffers are initially empty, i.e.

$$
s_{i, 0}=0, \forall i \geq 0
$$

The production capacity constraints can be expressed as follows :

$$
0 \leq \mathrm{u}_{\mathrm{i}, \mathrm{t}} \leq \mathrm{W}_{\mathrm{i}}, \forall \mathrm{i} \geq 0, \forall \mathrm{t}
$$

Without loss of generality, we assume that one component of each type is needed to obtain a finished product, i.e. $q_{i}=1$. The buffer levels can be determined as follows :

$$
\mathrm{s}_{\mathrm{i}, \mathrm{t}}=\mathrm{s}_{\mathrm{i}, \mathrm{t}-1}+\mathrm{u}_{\mathrm{i}, \mathrm{t}}-\mathrm{u}_{0, \mathrm{t}}, \forall 1 \leq \mathrm{i} \leq \mathrm{n}, \forall \mathrm{t}
$$

and

$$
s_{0, t}=s_{0, t-1}+u_{0, t}-d_{t}, \forall t
$$


Since the levels of the intermediate buffers are positive and since backlogging of the demand is not allowed, we have :

$$
s_{i, t} \geq 0, \forall i \geq 0, \forall t
$$

The total cost incurred by the buffer levels is given by :

$$
\sum_{i=0}^{n} \sum_{t=1}^{H} c_{i} s_{i, t}
$$

The flow control problem consists of choosing $u_{i, t} \forall i$ and $\forall t$ so as to

$$
\operatorname{minimize} \sum_{i=0}^{n} \sum_{t=1}^{H} c_{i} s_{i, t}
$$

subject to the constraints (1) - (5).

Finally, without loss of generality, we assume that :

$$
\mathrm{W}_{1} \leq \mathrm{W}_{2} \ldots \leq \mathrm{W}_{\mathrm{n}}
$$

In the following, we first present the solution for the case of single machine. We then address the two-level case.

\section{SINGLE MACHINE CASE}

This section summarizes some results presented in [6]. In the single machine case, we can neglect the index concerning the machines and the buffers and the problem becomes :

$$
\operatorname{minimize} \sum_{\mathrm{t}=1}^{\mathrm{H}} \mathrm{cs}
$$

subject to the following constraints :

$$
\begin{aligned}
& 0 \leq \mathrm{u}_{\mathrm{t}} \leq \mathrm{W}, \forall \mathrm{t} \\
& \mathrm{s}_{\mathrm{t}}=\mathrm{s}_{\mathrm{t}-1}+\mathrm{u}_{\mathrm{t}}-\mathrm{d}_{\mathrm{t}}, \forall \mathrm{t} \\
& \mathrm{s}_{\mathrm{t}} \geq 0, \forall \mathrm{t} \\
& \mathrm{s}_{0}=0
\end{aligned}
$$

As can be noticed, the optimal control policy is independent of the inventory holding cost $c$ and we denote the problem (8) as $\operatorname{SMP}\left(W,\left[d_{t}\right]\right)$ in the following.

Let us consider a mapping $\left[\sigma_{\mathrm{t}}\right]=\Phi\left(\mathrm{W},\left[\mathrm{d}_{\mathrm{t}}\right]\right): \mathrm{IR} \times \mathrm{IR}^{\mathrm{H}} \rightarrow \mathrm{IR}^{\mathrm{H}+1}$ defined as follows:

$$
\sigma_{\mathrm{t}-1}=\left(\sigma_{\mathrm{t}}+\mathrm{d}_{\mathrm{t}}-\mathrm{W}\right)^{+}, \quad \forall 1 \leq \mathrm{t} \leq \mathrm{H}
$$

where

$$
\sigma_{\mathrm{H}}=0
$$


Consider also another mapping $\left[v_{\mathrm{t}}\right]=\Psi\left(\mathrm{W},\left[\mathrm{d}_{\mathrm{t}}\right]\right): \operatorname{IR} \times \mathrm{IR}^{\mathrm{H}} \rightarrow \mathrm{IR}^{\mathrm{H}}$ defined as follows:

$$
v_{\mathrm{t}}=\operatorname{Min}\left\{\mathrm{W}, \sigma_{\mathrm{t}}+\mathrm{d}_{\mathrm{t}}\right\}, \quad \forall 1 \leq \mathrm{t} \leq \mathrm{H}
$$

Theorem 1.

The demand is feasible iff $\sigma_{0}=0$. In case of a feasible demand, $\Psi\left(W,\left[d_{t}\right]\right)$ and $\Phi\left(W,\left[d_{t}\right]\right)$ provide the optimal control policy and the optimal inventory trajectory respectively.

As it can be noticed, the optimal control policy consists of producing as late as possible, and this policy leads to lowest inventory levels over the whole horizon. Furthermore, this control policy has the following properties:

Property 1.
(a) $\sigma_{\mathrm{t}-1}=\operatorname{Max}\left\{0, \operatorname{Max}_{\mathrm{t} \leq \tau \leq \mathrm{H}}\left\{\sum_{\mathrm{s}=\mathrm{t}}^{\tau} \mathrm{d}_{\mathrm{s}}-(\tau-\mathrm{t}+1) \mathrm{W}\right\}\right\}, \forall 1 \leq \mathrm{t} \leq \mathrm{H}$
(b) $\sigma_{\mathrm{t}}=\sigma_{\mathrm{t}-1}+v_{\mathrm{t}}-\mathrm{d}_{\mathrm{t}}, \quad \forall 1 \leq \mathrm{t} \leq \mathrm{H}$
(c) $0 \leq v_{\mathrm{t}} \leq \mathrm{W}, \quad \forall 1 \leq \mathrm{t} \leq \mathrm{H}$.

Property 2.

In case of feasible demand, let $\left[\mathrm{s}_{\mathrm{t}}\right]$ be the inventory trajectory of a feasible solution to the problem $\operatorname{SMP}\left(W,\left[d_{t}\right]\right)$. Then,

$$
\mathrm{s}_{\mathrm{t}} \geq \sigma_{\mathrm{t}}, \quad \forall 0 \leq \mathrm{t} \leq \mathrm{H}
$$

From Property 1.a., it is obvious that the mapping $\Phi\left(W,\left[d_{t}\right]\right)$ is non-increasing in the machine capacity $\mathrm{W}$.

\section{Property 3.}

Consider two production capacities $W_{1}$ and $W_{2}$ with $W_{1} \geq W_{2} \geq 0$. The inventory level is always higher under the control $\Psi\left(W_{2},\left[d_{t}\right]\right)$ than under the control $\Psi\left(W_{1},\left[d_{t}\right]\right)$. Furthermore, the machine produces under $\Psi\left(\mathrm{W}_{2},\left[\mathrm{~d}_{\mathrm{t}}\right]\right)$ whenever it produces under $\Psi\left(\mathrm{W}_{1},\left[\mathrm{~d}_{\mathrm{t}}\right]\right)$. That is :
(a) $\Phi\left(\mathrm{W}_{1},\left[\mathrm{~d}_{\mathrm{t}}\right]\right) \leq \Phi\left(\mathrm{W}_{2},\left[\mathrm{~d}_{\mathrm{t}}\right]\right)$
(b) $v_{\mathrm{t}}^{2}>0$ whenever $v_{\mathrm{t}}^{1}>0$

where $\left[v_{\mathrm{t}}^{1}\right]=\Psi\left(\mathrm{W}_{1},\left[\mathrm{~d}_{\mathrm{t}}\right]\right)$ and $\left[v_{\mathrm{t}}^{2}\right]=\Psi\left(\mathrm{W}_{2},\left[\mathrm{~d}_{\mathrm{t}}\right]\right)$

From Property 1, it can be easily shown that if the demand is always lower than the capacity, then the inventory is always empty and the machine follows the demand. 


\section{Property 4.}

If $d_{t} \leq W$ for all $t$, then $\Phi\left(W,\left[d_{t}\right]\right)=[0]$ and $\Psi\left(W,\left[d_{t}\right]\right)=\left[d_{t}\right]$.

\section{Property 5.}

For any two positive numbers $W_{1}$ and $W_{2}$, it holds that.

$$
\Psi\left(W_{2}, \Psi\left(W_{1},\left[d_{t}\right]\right)\right)=\Psi\left(\operatorname{Min}\left\{W_{1}, W_{2}\right\},\left[d_{t}\right]\right)
$$

\section{TWO-LEVEL CASE}

In this section, we first address the feasibility of the demand, and the characteristics of the optimal control policies. We then address the optimal control in different possible cases depending on the inventory holding costs or the production capacity.

\subsection{Demand feasibility}

The feasibility of the demand depends on the machine with the smallest production capacity called bottleneck machine. We prove in the following that the demand is feasible iff it is in the case of single machine whose capacity is that of the bottleneck machine. The demand feasibility condition established in the single machine case can be used to check the demand feasibility of the general case.

Let

$$
\underline{W}=\underset{0 \leq i \leq n}{\operatorname{Min}} W_{i}
$$

and

$$
\underline{c}=\operatorname{Min}_{0 \leq i \leq n} c_{i}
$$

Theorem 2.

The demand is feasible iff the single machine problem $\operatorname{SMP}\left(\underline{\mathrm{W}},\left[\mathrm{d}_{\mathrm{t}}\right]\right)$ has at least one feasible solution.

\section{Proof :}

Let $\mathrm{M}_{\mathrm{m}}$ be the bottleneck machine, i.e.

$$
W_{m}=\underset{0 \leq i \leq n}{\operatorname{Min}} W_{i}
$$

For any feasible control $\left[u_{i, t}\right]$ of the general case, $\left[u_{m, t}\right]$ is clearly a feasible control of the single machine case $\operatorname{SMP}\left(\mathrm{W}_{\mathrm{m}},\left[\mathrm{d}_{\mathrm{t}}\right]\right)$.

On the other hand, for any feasible control $\left[v_{t}\right]$ of $\operatorname{SMP}\left(W_{m},\left[d_{t}\right]\right)$ and its related inventory trajectory $\left[\sigma_{t}\right]$, the control policy $\left[u_{i, t}\right]$ with $u_{i, t}=v_{t} \forall i$ and $\forall t$ is a feasible control because of the following relations : 


$$
\begin{aligned}
& 0 \leq \mathrm{u}_{\mathrm{i}, \mathrm{t}}=\mathrm{v}_{\mathrm{t}} \leq \mathrm{W}_{\mathrm{m}} \leq \mathrm{W}_{\mathrm{i}}, \forall \mathrm{i} \text { and } \forall \mathrm{t} \\
& \mathrm{s}_{\mathrm{i}, \mathrm{t}}=0, \forall 1 \leq \mathrm{i} \leq \mathrm{n}, \forall \mathrm{t} \\
& \mathrm{s}_{0, \mathrm{t}}=\sigma_{\mathrm{t}} \geq 0, \forall \mathrm{t}
\end{aligned}
$$

where $\left[s_{i, t}\right]$ are the inventory level trajectories related to the control $\left[u_{i, t}\right]$.

Q.E.D.

In the following, we assume that the demand is feasible.

\subsection{Characteristics of the optimal control policy}

The purpose of this section is to establish some characteristics of the optimal control policy which will be used to derive the optimal control policy.

First, let us notice that whenever the control of the assembly machine is known, the optimal control of the upper level machines can be determined as in the single machine case with demand replaced by the the control of the assembly machine.

Theorem 3.

Let $\left[u_{i, t}^{*}\right]$ be an optimal control policy and $\left[s_{i, t}^{*}\right]$ the related inventory trajectories. Then,
(a) $\quad\left[\mathrm{u}_{\mathrm{i}, \mathrm{t}}^{*}\right]=\Psi\left(\mathrm{W}_{\mathrm{i}},\left[\mathrm{u}_{0, \mathrm{t}}^{*}\right]\right), \quad \forall 1 \leq \mathrm{i} \leq \mathrm{n}$
(b) $\quad\left[\mathrm{s}_{\mathrm{i}, \mathrm{t}}^{*}\right]=\Phi\left(\mathrm{W}_{\mathrm{i}},\left[\mathrm{u}_{0, \mathrm{t}}^{*}\right]\right), \quad \forall 1 \leq \mathrm{i} \leq \mathrm{n}$
(c) $\quad\left[s_{i, t}^{*}\right] \geq\left[s_{i+1, t}^{*}\right], \quad \forall 1 \leq \mathrm{i} \leq \mathrm{n}-1$

Similar results have been obtained for continuous time model in [9] and the proof of Theorem 3.a. is similar to that of these results. Theorem 3.b. is a direct consequence of Theorem 3.a. and Theorem 3.c. can be proved by combining Theorem 3.b. and Property 3.

From Theorem 3 and Property 4, the following result can be easily proved.

Corollary 1.

$$
\left[\mathrm{u}_{\mathrm{i}, \mathrm{t}}^{*}\right]=\left[\mathrm{u}_{0, \mathrm{t}}^{*}\right] \text { and } \quad\left[\mathrm{s}_{\mathrm{i}, \mathrm{t}}^{*}\right]=[0], \quad \text { if } \mathrm{W}_{\mathrm{i}} \geq \mathrm{W}_{0}
$$

\subsection{Case : $\mathbf{W}_{0}=\underline{W}$}

It corresponds to the case in which the assembly machine is the bottleneck machine.

Theorem 4.

If $W_{0}=\underline{W}$, then the optimal control policy is given by : 


$$
\mathrm{s}_{\mathrm{i}, \tau}^{*} \geq \mathrm{s}_{\mathrm{N}, \tau}^{*}, \quad \forall 1 \leq \mathrm{i} \leq \mathrm{N}
$$

As all the buffers are empty by the end of problem horizon under the optimal control policy, there exists a period $k>t$ such that

$$
u_{0, k}^{*}>0
$$

Consider another control policy $\left[u_{i, t}\right]$ defined as follows: $\left[u_{i, t}\right]$ is identical to $\left[u_{i, t}^{*}\right]$ except at the following points :

$$
\begin{aligned}
& u_{0, \tau}=u_{N+1, \tau}=\ldots=u_{n, \tau}=u_{0, \tau}^{*}+\Delta \\
& u_{0, k}=u_{N+1, k}=\ldots=u_{n, k}=u_{0, k}^{*}-\Delta
\end{aligned}
$$

Since $W_{N} \leq W_{0}$, the definition of $\tau$ implies that :

$$
\mathrm{u}_{0, \tau}^{*}=\mathrm{u}_{\mathrm{N}, \tau}^{*}-\mathrm{s}_{\mathrm{N}, \tau}^{*} \leq \mathrm{W}_{0}-\mathrm{s}_{\mathrm{N}, \tau}^{*}
$$

Clearly, the new control policy is feasible for all $\Delta \leq \operatorname{Min}\left\{s_{N, \tau}^{*}, u_{0, k}^{*}\right\}$ and its related inventory trajectories $\left[s_{i, t}\right]$ are identical to $\left[s_{i, t}^{*}\right]$ except at the following points :

$$
\begin{array}{ll}
\mathrm{s}_{\mathrm{i}, \mathrm{t}}=\mathrm{s}_{\mathrm{i}, \mathrm{t}}^{*}-\Delta, & \forall 1 \leq \mathrm{i} \leq \mathrm{N}, \forall \tau \leq \mathrm{t}<\mathrm{k} \\
\mathrm{s}_{0, \mathrm{t}}=\mathrm{s}_{0, \mathrm{t}}^{*}+\Delta, & \forall \tau \leq \mathrm{t}<\mathrm{k}
\end{array}
$$

Comparing the total costs of these two control policies, we obtain :

$$
\begin{aligned}
& \sum_{i=0}^{n} \sum_{t=1}^{H} c_{i} s_{i, t}=\sum_{i=0}^{n} \sum_{t=1}^{H} c_{i} s_{i, t}^{*}+\sum_{t=\tau}^{k-1}\left(c_{0} \Delta-\sum_{i=1}^{N} c_{i} \Delta\right) \\
& =\sum_{i=0}^{n} \sum_{t=1}^{H} c_{i} s_{i, t}^{*}+\Delta(k-\tau)\left[c_{0}-\left(c_{1}+c_{2}+\ldots+c_{N}\right)\right] \\
& <\sum_{i=0}^{n} \sum_{t=1}^{H} c_{i} s_{i, t}^{*}
\end{aligned}
$$

This contradicts the optimality of $\left[u_{i, t}^{*}\right]$.

Q.E.D.

Let us define the following two quantities :

$$
\begin{aligned}
& N^{*}=\operatorname{Min}\{N, J\} \\
& W^{*}= \begin{cases}W_{0}, & \text { if } N^{*}=n ; \\
\operatorname{Min}\left\{W_{0}, W_{N^{*}+1}\right\}, & \text { otherwise. }\end{cases}
\end{aligned}
$$

Theorem 7.

If $c_{1}<c_{0}$ and $W_{0}>\underline{W}$ the optimal control policy is given by :

$$
\left[\mathrm{u}_{\mathrm{i}, \mathrm{t}}^{*}\right]=\left[\mathrm{u}_{0, \mathrm{t}}^{*}\right]=\Psi\left(\mathrm{W}^{*},\left[\mathrm{~d}_{\mathrm{t}}\right]\right), \quad \forall \mathrm{N}^{*}<\mathrm{i} \leq \mathrm{n}
$$

and

$$
\left[u_{i, t}^{*}\right]=\Psi\left(W_{i},\left[d_{t}\right]\right), \quad \forall i \leq N^{*}
$$


where $N^{*}$ and $W^{*}$ are defined as in equations (20) and (21). The buffer $B_{N^{*}+1}, \ldots, B_{n}$ are always empty, i.e.

$$
\left[\mathrm{s}_{\mathrm{i}, \mathrm{t}}^{*}\right]=[0], \quad \forall \mathrm{N}^{*}<\mathrm{i} \leq \mathrm{n}
$$

Proof :

The control $\left[u_{i, t}^{*}\right]$ is trivially a feasible control and the related inventory trajectories can be determined as follows :

$$
\begin{aligned}
& {\left[\mathrm{s}_{0, \mathrm{t}}^{*}\right]=\Phi\left(\mathrm{W}^{*},\left[\mathrm{~d}_{\mathrm{t}}\right]\right)} \\
& {\left[\mathrm{s}_{\mathrm{i}, \mathrm{t}}^{*}\right]=\Phi\left(\mathrm{W}_{\mathrm{i}},\left[\mathrm{d}_{\mathrm{t}}\right]\right)-\Phi\left(\mathrm{W}^{*},\left[\mathrm{~d}_{\mathrm{t}}\right]\right), \quad \forall \mathrm{i} \leq \mathrm{N}^{*}} \\
& {\left[\mathrm{~s}_{\mathrm{i}, \mathrm{t}}^{*}\right]=[0], \quad \forall \mathrm{N}^{*}<\mathrm{i} \leq \mathrm{n}}
\end{aligned}
$$

Let us prove the optimality. Consider a feasible control $\left[\mathrm{u}_{\mathrm{i}, \mathrm{t}}\right]$ and its related inventory trajectories $\left[s_{i, t}\right]$ and assume that they satisfy the optimality condition of Theorem 6 .

We notice that the control of machine $M_{i}$, i.e. $\left[u_{i, t}\right]$ for any $1 \leq i \leq N^{*}$ is a feasible control of the single machine case $\operatorname{SMP}\left(\mathrm{W}_{\mathrm{i}},\left[\mathrm{d}_{\mathrm{t}}\right]\right)$ and that $\left[\mathrm{u}_{0, \mathrm{t}}\right]$ is a feasible control of the single machine case $\operatorname{SMP}\left(W^{*},\left[d_{t}\right]\right)$. From Theorem 1 , we have :

$$
\begin{aligned}
& s_{i, t}+s_{0, t} \geq s_{i, t}^{*}+s_{0, t}^{*}, \quad \forall t, \forall 1 \leq i \leq N^{*} \\
& s_{0, t} \geq s_{0, t}^{*}, \quad \forall t
\end{aligned}
$$

Furthermore, since the inventory levels are non-negative, then

$$
s_{i, t} \geq s_{i, t}^{*}=0, \quad \forall t, \forall i>N^{*}
$$

By multiplying relations (22) by $c_{i}$, relations (23) by $\left(c_{0}-c_{1}-c_{2}-\ldots-c_{N^{*}}\right)$ and relations (24) by $c_{i}$ and then adding up these relations, we obtain :

$$
\sum_{i=0}^{n} c_{i} s_{i, t} \geq \sum_{i=0}^{n} c_{i} s_{i, t}^{*}, \quad \forall t
$$

which implies the optimality of $\left[u_{i, t}^{*}\right]$.

Q.E.D.

Finally, let us notice that the three cases addressed in subsections 4.3., 4.4. and 4.5. covered all possible cases. The optimal control policy is given by Theorem 4 , Theorem 5 and Theorem 7 respectively.

\section{A NUMERICAL EXAMPLE}

Consider an example of 11 upper level machines and 10 elementary periods, i.e. $n=11$ and $\mathrm{H}=10$. The production capacity and the inventory holding costs are given in Table 1. 


\begin{tabular}{|c|c|c|c|c|c|c|c|c|c|c|c|c|}
\hline $\mathrm{i}$ & 0 & 1 & 2 & 3 & 4 & 5 & 6 & 7 & 8 & 9 & 10 & 11 \\
\hline $\mathrm{W}_{\mathrm{i}}$ & 10 & 5 & 8 & 8 & 8 & 9 & 10 & 11 & 11 & 11 & 11 & 11 \\
\hline $\mathrm{c}_{\mathrm{i}}$ & 10 & 3 & 5 & 10 & 1 & 9 & 7 & 5 & 9 & 9 & 10 & 7 \\
\hline
\end{tabular}

Table 1: Production capacity and inventory holding cost

The demand is $\left[d_{t}\right]=[2,1,3,3,7,2,2,10,12,4]$. The minimal production capacity is equal to 5 and the demand is feasible.

Since $W_{0}>W_{1}$ and $c_{0}>c_{1}$, let us apply Theorem 7 to find the optimal solution. First, we obtain :

$N=5, J=2, N^{*}=\operatorname{Min}\{N, J\}=2, W^{*}=W_{3}=8$.

Thus, the optimal control and the related inventory trajectories are given by :

$$
\begin{aligned}
& {\left[\mathrm{u}_{\mathrm{i}, \mathrm{t}}^{*}\right]=\left[\mathrm{u}_{0, \mathrm{t}}^{*}\right]=\Psi\left(8,\left[\mathrm{~d}_{\mathrm{t}}\right]\right), \quad \forall 2<\mathrm{i} \leq 11} \\
& {\left[\mathrm{u}_{1, \mathrm{t}}^{*}\right]=\Psi\left(5,\left[\mathrm{~d}_{\mathrm{t}}\right]\right)} \\
& {\left[\mathrm{u}_{2, \mathrm{t}}^{*}\right]=\Psi\left(8,\left[\mathrm{~d}_{\mathrm{t}}\right]\right)}
\end{aligned}
$$

and

$$
\begin{aligned}
& {\left[s_{0, t}^{*}\right]=\Phi\left(8,\left[d_{t}\right]\right)} \\
& {\left[s_{1, t}^{*}\right]=\Phi\left(5,\left[d_{t}\right]\right)-\Phi\left(8,\left[d_{t}\right]\right)} \\
& {\left[s_{2, t}^{*}\right]=\Phi\left(8,\left[d_{t}\right]\right)-\Phi\left(8,\left[d_{t}\right]\right)=[0]} \\
& {\left[s_{i, t}^{*}\right]=[0], \quad \forall 2<i \leq 11}
\end{aligned}
$$

The optimal control policy is given in Table 2.

\begin{tabular}{|c|c|c|c|c|c|c|c|c|c|c|c|c|}
\hline$t \backslash \mathrm{i}$ & 0 & 1 & 2 & 3 & 4 & 5 & 6 & 7 & 8 & 9 & 10 & 11 \\
\hline 0 & $0 ; 0$ & $0 ; 0$ & $0 ; 0$ & $0 ; 0$ & $0 ; 0$ & $0 ; 0$ & $0 ; 0$ & $0 ; 0$ & $0 ; 0$ & $0 ; 0$ & $0 ; 0$ & $0 ; 0$ \\
\hline 1 & $0 ; 2$ & $0 ; 2$ & $0 ; 2$ & $0 ; 2$ & $0 ; 2$ & $0 ; 2$ & $0 ; 2$ & $0 ; 2$ & $0 ; 2$ & $0 ; 2$ & $0 ; 2$ & $0 ; 2$ \\
\hline 2 & $0 ; 1$ & $4 ; 5$ & $0 ; 1$ & $0 ; 1$ & $0 ; 1$ & $0 ; 1$ & $0 ; 1$ & $0 ; 1$ & $0 ; 1$ & $0 ; 1$ & $0 ; 1$ & $0 ; 1$ \\
\hline 3 & $0 ; 3$ & $6 ; 5$ & $0 ; 3$ & $0 ; 3$ & $0 ; 3$ & $0 ; 3$ & $0 ; 3$ & $0 ; 3$ & $0 ; 3$ & $0 ; 3$ & $0 ; 3$ & $0 ; 3$ \\
\hline 4 & $0 ; 3$ & $8 ; 5$ & $0 ; 3$ & $0 ; 3$ & $0 ; 3$ & $0 ; 3$ & $0 ; 3$ & $0 ; 3$ & $0 ; 3$ & $0 ; 3$ & $0 ; 3$ & $0 ; 3$ \\
\hline 5 & $0 ; 7$ & $6 ; 5$ & $0 ; 7$ & $0 ; 7$ & $0 ; 7$ & $0 ; 7$ & $0 ; 7$ & $0 ; 7$ & $0 ; 7$ & $0 ; 7$ & $0 ; 7$ & $0 ; 7$ \\
\hline 6 & $0 ; 2$ & $9 ; 5$ & $0 ; 2$ & $0 ; 2$ & $0 ; 2$ & $0 ; 2$ & $0 ; 2$ & $0 ; 2$ & $0 ; 2$ & $0 ; 2$ & $0 ; 2$ & $0 ; 2$ \\
\hline 7 & $6 ; 8$ & $6 ; 5$ & $0 ; 8$ & $0 ; 8$ & $0 ; 8$ & $0 ; 8$ & $0 ; 8$ & $0 ; 8$ & $0 ; 8$ & $0 ; 8$ & $0 ; 8$ & $0 ; 8$ \\
\hline 8 & $4 ; 8$ & $3 ; 5$ & $0 ; 8$ & $0 ; 8$ & $0 ; 8$ & $0 ; 8$ & $0 ; 8$ & $0 ; 8$ & $0 ; 8$ & $0 ; 8$ & $0 ; 8$ & $0 ; 8$ \\
\hline 9 & $0 ; 8$ & $0 ; 5$ & $0 ; 8$ & $0 ; 8$ & $0 ; 8$ & $0 ; 8$ & $0 ; 8$ & $0 ; 8$ & $0 ; 8$ & $0 ; 8$ & $0 ; 8$ & $0 ; 8$ \\
\hline 10 & $0 ; 4$ & $0 ; 4$ & $0 ; 4$ & $0 ; 4$ & $0 ; 4$ & $0 ; 4$ & $0 ; 4$ & $0 ; 4$ & $0 ; 4$ & $0 ; 4$ & $0 ; 4$ & $0 ; 4$ \\
\hline
\end{tabular}

Table 2: The optimal control policy $\left(s_{i, t}, u_{i, t}\right)$ 


\section{CONCLUSION}

In this paper, we have addressed the optimal flow control for two-level assembly production lines composed of a unique assembly machine and several upper level machines. We consider the case in which the production capacities are constant and the demand is known over the whole horizon. Properties of the optimal control policies have been established. In particular, some sufficient conditions under which the component buffers are always empty have been proposed. We also established some sufficient conditions under which a particular buffer is always empty. Finally, a simple algorithm has been proposed for computing the optimal control policy.

Future research work consists of extending the results to other manufacturing systems. We believe that similar results can be obtained for multi-level assembly systems.

\section{REFERENCES}

[1] R. Akella, Y. F. Choong, and S. B. Gershwin, "Performance of Hierarchical Production Scheduling Policy," IEEE Trans. on Components, Hybrids, and Manufacturing Technology, Vol. CHMT-7, No. 3, September, 1984.

[2] S. Axsäter, "Aggregation of Product Data for Hierarchical Production Planning," Operation Research, Vol. 29, No. 4, 1981

[3] A. Bensoussan, M. Crouchy and J.M. Proth, "Mathematical Theory of Production Planing," in Advanced Series in Management, North Holland Publishing, 1983

[4] G. R. Bitran, E. A. Haas, and A. C. Hax, "Hierarchical Production Planning: A Single Stage System," Operation Research, Vol. 29, No. 4, July-August, 1981

[5] S. B. Gershwin, "Hierarchical Flow Control: A Hierarchical Framework for Scheduling and Planning Discrete Events in Manufacturing Systems," Proceedings of IEEE, Vol. 77, No. 1, pp. 195-209, 1989.

[6] A. Haouba, and X.L. Xie, "Flow Control of Production Lines," submitted, 1993

[7] A. C. Hax, and H. C. Meal, "Hierarchical Integration of Production Planning and Scheduling," M.A.Geisler, ed. In Studies in Management Sciences, Vol. I, Logistics. North Holland-Americain Elsevier, 1975, pp. 53-69 
[8] J. Kimemia, and S. B. Gershwin, "An Algorithm for the Computer Control of a Flexible Manufacturing System," IIE Trans., Vol. 15, No. 4, December 1983.

[9] C. Libosvar, "Hierarchical Production Management: The Flow-Control Layer," Ph.D. Thesis, University of Metz, Metz, France, 1988.

[10] X.L. Xie, "Real Time Scheduling and Routing for Flexible Manufacturing Systems with Unreliable Machines," RAIRO Recherche Opérationnelle, vol. 23, no 4, p. 355-374, 1989

[11] X.L. Xie, "Hierarchical Production Control of a Flexible Manufacturing System," Applied Stochastic Models and Data Analysis, vol. 7, no. 4, p. 343-360, 1991. 


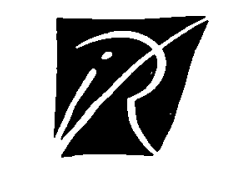

Unité de Recherche INRIA Lorraine

Technopôle de Nancy-Brabois - Campus Scientifique

615, rue du Jardin Botanique - B.P. 101 - 54602 VILLERS LES NANCY Cedex (France)

Unité de Recherche INRIA Rennes IRISA. Campus Lniversitaire de Beaulieu 35042 RENNES Cedex (France) Unité de Recherche INRIA Rhône-Alpes 46, avenue Félix Viallet - 38031 GRENOBLE Cedex (France)

Unité de Recherche INRIA Rocquencourt Domaine de Voluceau - Rocquencourt - B.P. I05 - 78153 LE CHESNAY Cedex (France)

Unité de Recherche INRIA Sophia Antipolis 2004, route des Lucioles - B.P. 93 - 06902 SOPHIA ANTIPOLIS Cedex (France)

\section{EDITEUR}

INRIA - Domaine de Voluceau - Rocquencourt - B.P. 105 - 78153 LE CHESNAY Cedex (France)

ISSN $0249-6399$ 